\title{
Comparable analysis of the distribution functions of runup heights of the 1896, 1933 and 2011 Japanese Tsunamis in the Sanriku area
}

\author{
B. H. Choi ${ }^{1}$, B. I. Min ${ }^{2}$, E. Pelinovsky ${ }^{3}$, Y. Tsuji ${ }^{4}$, and K. O. Kim ${ }^{5}$ \\ ${ }^{1}$ Department of Civil and Environmental Engineering, Sungkyunkwan University, Suwon, Korea \\ ${ }^{2}$ Nuclear Environment Safety Research Division, Korea Atomic Energy Research Institute, P.O. Box 105, Yuseong, Daejeon, \\ 305-600, Korea \\ ${ }^{3}$ Department of Nonlinear Geophysical Processes, Institute of Applied Physics, Nizhny Novgorod, Russia \\ ${ }^{4}$ Earthquake Research Institute, Tokyo University, Tokyo, Japan \\ ${ }^{5}$ Korea Ocean Research \& Development Institute, Ansan, Korea
}

Correspondence to: E. Pelinovsky (pelinovsky@hydro.appl.sci-nnov.ru)

Received: 7 December 2011 - Revised: 12 March 2012 - Accepted: 22 March 2012 - Published: 16 May 2012

\begin{abstract}
Data from a field survey of the 2011 Tohoku-oki tsunami in the Sanriku area of Japan is used to plot the distribution function of runup heights along the coast. It is shown that the distribution function can be approximated by a theoretical log-normal curve. The characteristics of the distribution functions of the 2011 event are compared with data from two previous catastrophic tsunamis (1896 and 1933) that occurred in almost the same region. The number of observations during the last tsunami is very large, which provides an opportunity to revise the conception of the distribution of tsunami wave heights and the relationship between statistical characteristics and the number of observed runup heights suggested by Kajiura (1983) based on a small amount of data on previous tsunamis. The distribution function of the 2011 event demonstrates the sensitivity to the number of measurements (many of them cannot be considered independent measurements) and can be used to determine the characteristic scale of the coast, which corresponds to the statistical independence of observed wave heights.
\end{abstract}

\section{Introduction}

A very strong earthquake $(M=9.0)$ occurred at $14 \mathrm{~h}$ $46 \mathrm{~m}$ (JST) on 11 March 2011 in the Pacific Sea. The event occurred east of the Tohoku district and near the northeast part of Honshu Island, Japan. A huge tsunami accompanied the earthquake; as of 14 July 2011, estimated 16011 people were killed and 5242 people are missing and presumed lost. The total of those numbers is 26347 , which is greater than the number of the victims of the 1896 Meiji Sanriku earth- quake tsunami (about 21 915). Many groups have conducted field surveys on the Sanriku coast, searched for traces of inundation limits, and measured the runup heights. First results of study of the 2011 Tohoku-oki earthquake and tsunami are now published (Koketsu et al., 2011; Fujii et al., 2011; Hayashi et al., 2011; Ozaki, 2011; Tsuji et al., 2011).

Many cities in this area have been affected by historic tsunamis. For instance, the town of Taro was hit by the Meiji Sanriku tsunami of 1896, in which 2859 people (about $95 \%$ of the total population) were killed. In 1933, this town was hit again by the Showa Sanriku tsunami, and 911 people were killed. The most recent tsunami entirely destroyed the newlyconstructed sea wall, and all of the wooden houses in the new town area were swept away; additionally, approximately 200 people were killed there. In the residential area of the old town, seawater flooded over the old sea wall and destroyed almost all wooden houses; fortunately few people were killed there.

Japan Society of Civil Engineers (JSCE) member groups performed post-tsunami runup surveys. The purpose of these surveys was to observe and document the effects of tsunamis, collect readily available but perishable data as soon as possible to learn about the nature and impact of the phenomenon, and enable recommendations on the need for further research, planning and preparedness. Data from these surveys have been compiled to provide geographical locations and runup heights online (http://www.coastal.jp/tsunami2011). This nationwide tsunami survey has been conducted by joint research groups of 299 researchers among 64 different universities/institutes. Inundation heights and run-up heights measured at 5.247 points in total (used data released on 

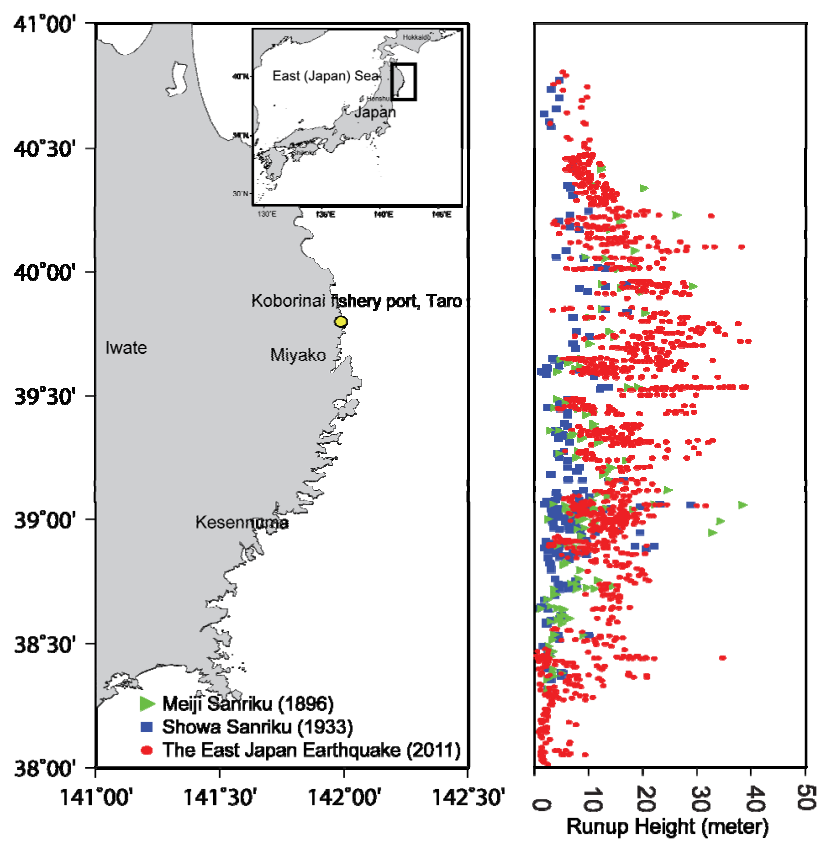

Fig. 1. Observed runup height distributions from the 1896, 1933, and 2011 tsunamis.

7 September 2011. The 2011 Tohoku Earthquake Tsunami Joint Survey Group, 2011).

The historical tsunami records of the Showa Sanriku (1933) and Meiji Sanriku (1896) tsunamis were collected from published sources, and the analysis of these two events were compared with those of the 2011 Tohoku-oki tsunami. Locations of post-tsunami runup surveys in Japan and a spatial distribution of the maximum heights are shown in Fig. 1. The characteristics of the observations are summarized in Table 1. At nine points on the $25 \mathrm{~km}$ of coast between the town of Yamada and the northern limit of Miyako City, seawater rose up to heights exceeding $30 \mathrm{~m}$.

However, measured maximum tsunami heights should be interpreted carefully because they are sometimes the heights of splash-up and are not representative of runup heights in a specific region. Even in a limited coastal region, the runup heights vary widely due to interactions between wave and coastal topography. As we demonstrate below, the conception of the distribution function can be useful to check observed data.

\section{Distribution Functions of the observed runup heights}

Numerical and statistical methods can be applied to analyze data and recover possible missing data. It is important to know the contribution of the highest wave height values, including missing data, to the total distribution of wave heights. Van-Dorn (1965) was the first to apply a statistical approach to analyze observed tsunami runup heights. He found that a log-normal distribution was the best fit for tsunamis on the coast of the Hawaiian Islands. This distribution (mathematically, a probability density function, pdf) has the following shape:

$f(H)=\frac{1}{H \sigma \sqrt{2 \pi} \ln 10} \exp \left(-\frac{(\log H-a)^{2}}{2 \sigma^{2}}\right)$

where $H$ is the maximum runup height for each point along the coast, measured in meters. This distribution has two parameters with evident physical characteristics: $a=\langle\log H\rangle$ is the average value of the wave height logarithm, and $\sigma$ is the standard deviation of the height logarithm.

This analysis was continued by Kajiura (1983) with a special focus on the Japanese coast. He analyzed 6 events: 1506-1896 Meiji Sanriku, 03-03-1933 Showa Sanriku, 12-211946 Nankaido, 05-23-1960 Chile, 06-16-1964 Niigata, and 05-16-1968 Tokashi-oki. Some of these events occurred in 1896 and 1933 in the Sanriku area in the same place as the 2011 event. Histograms of the observed tsunami runups in the total range of about $300 \mathrm{~km}$ of the coastal stretch for each event were approximated by the log-normal curve (1), and parameters of the distribution were determined and are given in Table 1. The distribution functions for Meiji Sanriku (1896) and Showa Sanriku (1933) are reproduced in Fig. 2. We plotted it for different intervals of the runup height from $0.5 \mathrm{~m}$, but only when the interval increases up to $4 \mathrm{~m}$, the correlation with the log-normal curve seems more evident. A similar histogram analysis was performed for the 2011 Tohoku-oki event based on field survey data; the histogram and log-normal approximation from this analysis are presented in Fig. 2.

Here we present data from three tsunamis; these data were obtained from different numbers of measurements. For the 1896 tsunami, the oldest event, 132 points of measurement were collected. For the 1933 event, data on runup heights were obtained in 205 coastal locations. In the most recent 2011 event, the number of coastal locations exceeds 5000 . In his analysis of the distribution functions of runup heights along the Japanese coast, Kajiura (1983) mentioned that the number of samples can influence the observed characteristics of the distribution function. Regarding the applicability of statistical approaches to the historic tsunamis, he concluded that "because of the strong dependence of tsunami behaviour along the coast on both the characteristics of the incoming tsunami wave train and the topographic conditions of local and regional scales, it is very difficult to draw general conclusions concerning the spatial statistics of coastal wave run-up heights applicable to all regions and tsunamis." In our opinion, the main problem with the use of log-normal distribution Eq. (1) is that the obtained histograms of runup heights with small intervals $(0.5-2 \mathrm{~m})$ do not coincide well with $\log$ normal approximations. A clear correlation is achieved only for large intervals $(4 \mathrm{~m})$ when the number of groups is relative small. Additionally, adding or eliminating new measured runup values can influence the statistical characteristics of 
Table 1. Characteristics of Sanriku tsunamis.

\begin{tabular}{llllll}
\hline & $\begin{array}{l}\text { Magnitude of } \\
\text { Earthquake }\end{array}$ & $\begin{array}{l}\text { Max Recorded } \\
\text { Height, H, m }\end{array}$ & $\begin{array}{l}\text { Mean } \\
\text { Log H }\end{array}$ & $\begin{array}{l}\text { Standard } \\
\text { Deviation Log H }\end{array}$ & $\begin{array}{l}\text { Number of } \\
\text { observed stations }\end{array}$ \\
\hline Meiji Sanriku (1896) & $8.5(\mathrm{Mw})$ & 38.2 & 0.881 & 0.309 & 132 \\
Showa Sanriku (1933) & $8.4(\mathrm{Mw})$ & 28.7 & 0.711 & 0.285 & 205 \\
Tohoku-oki Earthquake (2011) & $9.0(\mathrm{Mw})$ & 40.4 & 0.937 & 0.394 & Over 5000 \\
\hline
\end{tabular}

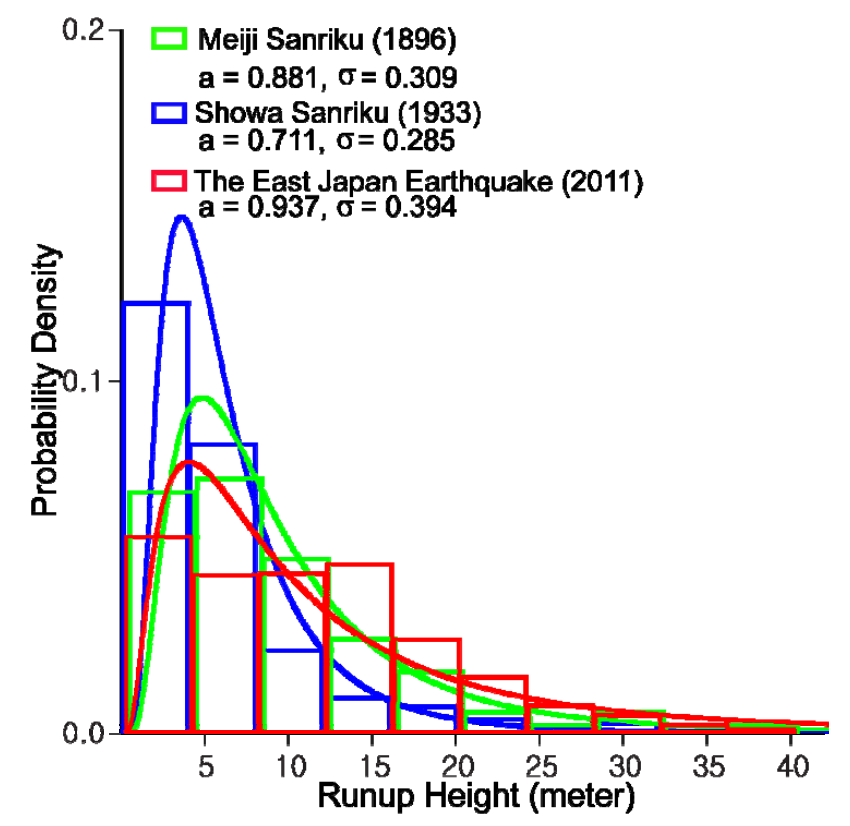

Fig. 2. Histograms of three tsunamis with interval $4 \mathrm{~m}$ of runup height.

runup distributions. This problem can be resolved with the use of integral forms of runup distributions (probability function or cumulative distribution), which can be obtained by the integration of probability density function Eq. (1).

The theoretical interpretation of the log-normal distribution of tsunami runup heights is associated with the random topography of the sea bottom (Go, 1997; Choi et al., 2002; Burroughs and Tebbens, 2005; Kaistrenko, 2011). In the simplified ray theory based on the linear shallow-water theory, the runup height, $H$, is taken as proportional to a wave height in the tsunami source (open ocean), $H_{o}$ :

$H=K H_{0}$

where $K$ is the transformation factor that depends on seadepth change along a propagation path and is determined by random seafloor topography only within these approximations. Dividing the propagation path over a series of more or less statistically independent segments, the total transformation coefficient is a product of the local coefficients of the tsunami transformation on each segment. In this case, formula Eq. (2) can be rewritten in the logarithm form:

$\log H=\log H_{0}+\sum_{i} \log K_{i}$

where $i$ characterizes the number of random statistically independent segments along the propagation path and $\log K_{i}$ can be considered as independent random variables. The central limit theorem states that the sum of many random independent variables tends to the Gaussian process, and therefore the wave height is described by the log-normal distribution Eq. (1). It is important to note here that measured data in all points should be statistically independent, but this is difficult to check experimentally. The characteristic correlation scale between different measured values cannot be determined theoretically; it should be done with an analysis of obtained data. As we show below, the distribution function can help determine this correlation scale.

Another important consideration is how we make the best comparison of distribution functions for different events. The correct scaling should be identified. Choi et al. (2002) suggested the use of a complementary cumulative distribution (probability) instead of probability density function (1)

$F(H)=\frac{1}{\sqrt{2 \pi} \ln 10 \sigma} \int_{H}^{\infty} \exp \left(-\frac{(\log h-a)^{2}}{2 \sigma^{2}}\right) \frac{d h}{h}$

Eq. (4) can be written in universal non-parametric form:

$F(\zeta)=\frac{1}{\sqrt{2 \pi} \ln 10} \int_{\zeta}^{\infty} \exp \left(-\frac{1}{2}(\log \theta)^{2}\right) \frac{d \theta}{\theta}$

where $\zeta=(H / \bar{H})^{1 / \sigma}, \bar{H}=10^{a}$. In fact, the cumulative distribution, or probability function Eq. (5) was used to analyze the distribution of runup heights in different countries during the 2004 tsunami in the Indian Ocean (Choi et al., 2006). The characteristics of this tsunami in Indonesia, Thailand, Malaysia, India, Sri Lanka were very different, but the cumulative distributions Eq. (5) written in dimensionless variables were very similar to one another (Choi et al., 2006).

We applied the same approach to analyze data from the 2011 Tohoku-oki event in comparison with the similarly huge historic events of 1896 and 1933. Figure 3 presents the cumulative distribution (probability) of these tsunami wave 


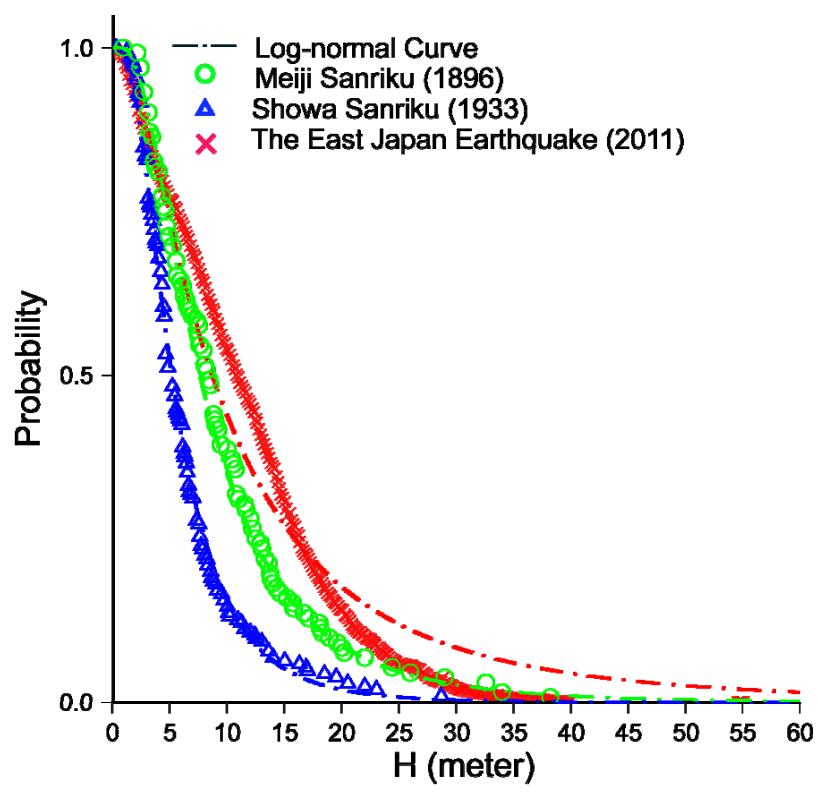

Fig. 3. Cumulative distribution (probability) for tsunamis runup heights. The symbols are each tsunami events. The solid lines are log-normal curves.

heights for the eastern coast of Japan as a whole and the theoretical curve Eq. (4). The distribution of the observed runup heights in 1896 and 1933 was described quite well by the theoretical function Eq. (4), but no such agreement was observed for the 2011 Tohoku-oki event. In our opinion, this can be explained by the large number of "dependent" measurement values (more than 5000) because the interval between some points was $100 \mathrm{~m}$ or less.

The influence of the spatial correlation scale of observation data is demonstrated in Fig. 4 where the probability function is plotted with different scales of averaging of observed runup heights. The spatial scale of $7.5 \mathrm{~km}$ provides the best comparison of the theoretical curve with observational data, and therefore this scale can determine the correlation length characterizing the independence of different locations of runup measurements.

\section{Conclusions}

We demonstrate that distribution functions of runup heights of three catastrophic tsunamis $(1896,1933$, and 2011) are very well fitted by log-normal curves based on the assumption of statistical independence of measured wave heights. In the case of the 2011 event, the number of measurements is too high (more than 5000), and some of the runup values are not independent. If runup heights are averaged with a spatial scale of $7.5 \mathrm{~km}$, the best correlation between theory and observations is obtained and this scale can therefore be considered the characteristic correlation scale.

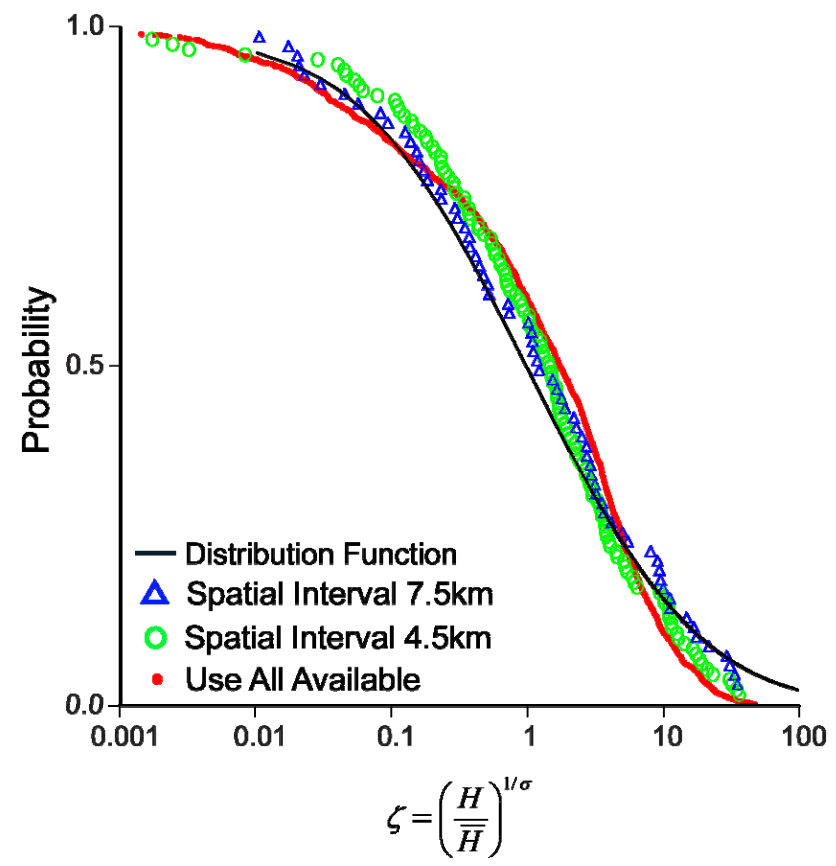

Fig. 4. Cummulative distribution (probability) of the 2011 Tohokuoki tsunami in dimensionless form. The dashed line corresponds to the log-normal curve. The circles and triangles represent spatial intervals of $4.5 \mathrm{~km}$ and $7.5 \mathrm{~km}$, respectively. The dots indicate the individual observed values (over 2000).

Acknowledgements. EP thanks RFBR grant (11-05-00216). KKO acknowledges the support by the project for the development of the marine environmental impact prediction system funded by KORDI. The useful comments by Eric Geist, Victor Kaistrenko and Stefano Tinti are acknowledged.

Edited by: S. Tinti

Reviewed by: E. Geist and V. Kaystrenko

\section{References}

Burroughs, S. M. and Tebbens, S. F.: Power-law scaling and probabilistic forecasting of tsunami runup heights, Pure Appl. Geophys., 162, 331-342, 2005.

Choi, B. H., Pelinovsky, E., Riabov, I., and Hong, S. J.: Distribution functions of tsunami wave heights, Nat. Hazards, 25, 1-21, 2002.

Choi, B. H., Hong, S. J., and Pelinovsky, E.: Distribution of runup heights of the December 26, 004 tsunami in the Indian Ocean, Geophys. Res. Lett., 33, 13, L13601, doi:10.1029/2006GL025867, 2006.

Fujii Y., Satake K., Sakai S., Shinohara M., and Kanazawa T.: Tsunami source of the 2011 off the Pacific coast of Tohoku Earthquake, Earth Planets Space, 63, 7, 815-820, 2011.

Go, Ch. N.: Statistical distribution of the tsunami heights along the coast, Tsunami and accompanied phenomena, Institute of Marine Geology and Geophysics, Sakhalin, 7, 73-79, 1997 (in Russian).

Hayashi, Y., Tsushima, H., Hirata, K., Kimura, K., and Maeda, K.: Tsunami source area of the 2011 off the Pacific coast of Tohoku 
Earthquake determined from tsunami arrival times at offshore observation stations, Earth Planets Space, 63, 809-813, 2011.

Kaistrenko V. M.: Tsunami recurrence versus tsunami height distribution along the coast, Pure Appl. Geophys., 168, 11, 20652069, 2011.

Kajiura, K.: Some statistics related to observed tsunami heights along the coast of Japan, Tsunamis - Their Science and Engineering, Terra Pub., Tokyo, 131-145, 1983.

Koketsu, K., Yokota, Y., Nishimura, N., Yagi, Y., Miyazaki, S., Satake, K., Fujii, Y., Miyake, H., Sakai, S., Yamanaka, Y., and Okada, T.: A unified source model for the 2011 Tohoku earthquake, Earth Planet. Sci. Lett., 310, 480-487, 2011
Ozaki, T.: Outline of the 2011 off the Pacific coast of Tohoku Earthquake $\left(M_{\mathrm{W}} 9.0\right)$ : Tsunami warnings/advisories and observations, Earth Planets Space, 63, 827-830, 2011.

The 2011 Tohoku Earthquake Tsunami Joint Survey Group.: Nationwide Field Survey of the 2011 Off the Pacific Coast of Tohoku Earthquake Tsunami, Journal of Japan Society of Civil Engineers, Series, 67, 1, 63-66, 2011.

Tsuji, T., Ito, Y., Kido, M., Osada, Y., Fujimoto, H., Ashi, J., Kinoshita, M., and Matsuoka, T.: Potential tsunamigenic faults of the 2011 off the Pacific coast of Tohoku Earthquake, Earth Planets Space, 63, 831-834, 2011.

Van Dorn, W. G.: Tsunamis, Advances in Hydroscience, edited by: Chow, V. T., Acad. Press, London, 2, 1-48, 1965. 